\title{
IMPLEMENTACIÓN DE UN SISTEMA DE GESTIÓN DE SEGURIDAD ALIMENTARIA EN UN CENTRO DE ELABORACIÓN DE FÓRMULAS LÁCTEAS INFANTILES DE UN HOSPITAL PÚBLICO PEDIÁTRICO DE ALTA COMPLEJIDAD
}

\author{
IMPLEMENTATION OF A FOOD SAFETY MANAGEMENT SYSTEM IN A \\ CENTER FOR THE DEVELOPMENT OF CHILDREN'S DAIRY FORMULAS \\ FROM A HIGH-COMPLEX PEDIATRIC PUBLIC HOSPITAL
}

\author{
Silvia Alejandra Marteau ${ }^{1,}$, Luis Héctor Perego ${ }^{2}$, María Cecilia Gaillard 3
}

\section{RESUMEN}

La alimentación que brindan los servicios de nutrición de los hospitales representa un pilar fundamental en la recuperación y/o mantenimiento de la salud del paciente hospitalizado. Por otra parte, cuando se habla de inocuidad, se piensa en un alimento que no representa ningún riesgo para la salud humana, lo cual indudablemente está ligado al término calidad. Para garantizar lo anterior hay que considerar una serie de factores que influyen a través de la cadena alimentaria. El propósito de este trabajo fue presentar una investigación proyectiva de potencialidades, que no se estaban aprovechando en el Centro de Elaboración de Fórmulas Lácteas Infantiles de un hospital púbico de alta complejidad, promoviendo la aplicación de los principios de la teoría de la gestión de la calidad, como primera etapa enfocado al aseguramiento de la inocuidad, a través de un sistema de gestión de seguridad alimentaria. El porcentaje de cumplimiento total del Centro en cuanto a las buenas prácticas de manufactura solamente alcanzo un $49 \%$. El mayor grado de incumplimiento estuvo asociado con la dimensión organización y administración en un 80 \%. Se logró mejorar sistemáticamente la información recopilada a partir de los nuevos documentos diseñados e incorporados en base de datos adecuadas para su posterior análisis, de tal manera que se posibilite una mejor y más eficiente toma de decisiones a los responsables del centro como así también programar y proyectar futuras demandas. Además, se consiguió incorporar productos de limpieza adecuados para su uso en la industria de los alimentos, el rediseño del proceso de elaboración de fórmulas lácteas en polvo y el aseguramiento de la inocuidad de la producción a través del sistema APPCC. Según los resultados de los análisis obtenidos, la implantación de un sistema de este tipo garantiza la inocuidad de los alimentos y por ende la calidad del servicio brindado.

Palabras Clave: Lactario, inocuidad, peligros, puntos críticos

\footnotetext{
${ }^{1}$ Comisión de Investigaciones Científicas (CIC), Centro de Investigación y Desarrollo en Crio tecnología de Alimentos (CIDCA), CONICET, Universidad Nacional de La Plata. La Plata. Argentina.orcid.org/0000-0002-1847-6803

${ }_{3}$ Departamento de Ingenieria Industrial, Universidad Tecnológica Nacional - Facultad Regional La Plata. La Plata. Argentina. orcid.org/0000-0002-3039-9724

Comisión de Investigaciones Científicas (CIC), Instituto de Investigaciones Pediátricas (IDIP), Ministerio de Salud provincia de Buenos Aires. La Plata. Argentina. orcid.org/0000-0002$5150-9654$
}

•Autor para correspondencia: samarteau@hotmail.com

Recibido:05.01.2017 Aceptado: 30.07.2017 


\section{ABSTRACT}

The nutrition provided by the hospital's nutrition services represents a fundamental pillar in the recovery and maintenance of hospitalized patient's health. On the other hand, when we talk about safety, we think of a food that does not pose any risk to human health, which is undoubtedly connected to the term quality. To ensure this, a number of factors have to be considered that influence the food chain. The purpose of this work was to present a projective research of potentialities, which is not being approved in the Center for the Development of Infant Milk Formulas of a hospital of high complexity, promoting the application of the principles of the theory of management of quality, as the first stage focused on safety assurance, through a food safety management system. The Center's overall compliance with good manufacturing practices only reached $49 \%$. The highest degree of noncompliance was associated with the size of the organization and administration by $80 \%$. It was possible to systematically improve the information collected from the new documents designed and incorporated in the database suitable for later analysis, such that a better and more efficient decision-making is possible for those responsible for the center as well as the projection of future demands. In addition, we incorporated the cleaning products suitable for use in the food industry, the redesign of the process of the manufacture of formulas and dust systems and the safety assurance of production through the HACCP system. According to the results of the analysis obtained, the implementation of such a system guarantees the safety of the food and the quality of the service provided.

Keywords: Breastfeeding, safety, dangers, critical points

\section{INTRODUCCION}

El argumento de la calidad parte de los propósitos y requisitos establecidos que debe cumplir cualquier organización y de la satisfacción de las necesidades de las personas a las cuales presta un servicio. En materia de salud, dar una respuesta efectiva a los problemas o situaciones de salud que inciden sobre una población y sus individuos, identificados o no por ellos y estableciendo o aplicando las normas, procedimientos y protocolos diagnósticoterapéuticos necesarios, verificando los instrumentos y medios médicos que se utilizan. (Amador Porro \& Cubero Menéndez, 2010). La calidad en la prestación de los servicios de salud es sin duda una preocupación medular en la gestión del sector, no solo por la aspiración a la mejora de las capacidades institucionales en los organismos y dependencias sectoriales, sino sobre todo porque en la totalidad de los procesos se encuentra la vida de las personas, cuya salud debe ser promovida y protegida como obligación insoslayable del Estado, a decir de Huiza Guardia (2006).

El servicio de nutrición de la unidad hospitalaria es el encargado y responsable de organizar y velar por el cumplimiento de las actividades relacionadas a un adecuado servicio de alimentación. En las instituciones pediátricas de alta complejidad que tienen como función la hospitalización de niños con patologías severas o graves, funciona, dentro del servicio de nutrición, un área destinada a la alimentación de estos pacientes. Desde esta área suministran preparaciones especiales a partir de fórmulas lácteas. (Bordon Riveros et al., 2016). La elaboración de este tipo de alimentación se desarrolla en sectores especiales denominados "lactarios". El lactario es el ambiente físico hospitalario destinado a la higiene, preparación y distribución de biberones con fórmulas lácteas, consignados a la alimentación de los recién nacidos o lactantes; su función principal se desarrolla cuando la lactancia materna no es 
posible, por lo que debe utilizarse las fórmulas adaptadas cuya composición está regulada según directrices de diversos organismos internacionales.

La lactancia materna es la alimentación más completa para el lactante, tanto en seguridad como calidad; otorga suficiencia de nutrientes, ayuda a prevenir infecciones, favorece el desarrollo global y disminuye la morbimortalidad infantil ${ }^{4}$. (Bustos et al., 2016); sin embargo, existen casos en donde es necesario administrar formulas ya sean por vía oral o enteral ${ }^{5}$ preparadas en forma bacteriológicamente segura en caso de que no pueda ser posible la lactancia materna. Empero, la elaboración de fórmulas lácteas está sujeta a diversos riesgos de contaminación. (Rachon et al., 2017 y Siqueira et al., 2013). En los hospitales, las técnicas inadecuadas de fabricación, recepción, almacenamiento, preparación y distribución de las fórmulas enterales constituyen un riesgo importante de infecciones asociadas a la atención de la salud. (Lara et al., 2013 y Parra et al., 2016).

El Sistema de Análisis de Peligros y de Puntos Críticos de Control (APPCC) aceptado por la Comisión del Codex Alimentarius (CCA), permite identificar los riesgos específicos y medidas de control, con el objetivo de garantizar la inocuidad y calidad de los alimentos. Es por ello por lo que tanto la Organización Mundial de la Salud (OMS), como la Organización para la Alimentación y la Agricultura (FAO) han emitido alertas y recomendaciones para su prevención, sugiriendo la estandarización y protocolización de todos los procedimientos involucrados, definiendo los puntos críticos que involucran un mayor riesgo de contaminación, tanto en la preparación como administración de las fórmulas lácteas, que garanticen su calidad e inocuidad. (FAO/OMS, 2009).

Argentina, a partir de la Guía de Calidad de los Servicios de Salud. Programa Nacional de Garantía de la Calidad de la Atención Médica. Guía Práctica Clínica de Soporte Nutricional Enteral y Parenteral en pacientes hospitalizados y domiciliarios del Ministerio de Salud de Argentina (2007), dispone de normas de elaboración y preparación de fórmulas lácteas y enterales al igual que Perú, Chile y Brasil que también presentan normativas similares. En la provincia de Buenos Aires, los establecimientos hospitalarios, ya sean de dependencia provincial o municipal, pertenecen a una Región Sanitaria, la que se define de acuerdo con su ubicación geográfica. Conforme al decreto $N^{\circ} 4790 / 72$ art. $6^{\circ}$ de la clasificación de hospitales, el hospital bajo estudio, perteneciente a la Región Sanitaria XI, está clasificado como un Hospital Interzonal Especializado de Agudos (HIEA). Dado que el HIEA se constituye como un hospital de alta complejidad pediátrica en la provincia de Buenos Aires, siendo un referente en mediana y alta complejidad con reconocimiento nacional e internacional, es que surge la necesidad imperiosa de adecuar los procesos siguiendo los lineamientos y normativas recomendadas por diversos organismos internacionales para garantizar en medida de lo posible que las fórmulas infantiles que se preparan en el Centro de Elaboración de Fórmulas Lácteas Infantiles (CEFLI) de la Unidad de alimentación del servicio de nutrición, y se consumen en el hospital sean seguras para la alimentación de los lactantes, sobre todo en las unidades de cuidados intensivos neonatales.

Este trabajo tuvo por objeto la aplicación de los principios de la teoría de la Gestión de Calidad a través de un Sistema de Gestión de Seguridad Alimentaria (SGSA), para en una primera etapa asegurar inocuidad en el CEFLI. De esta manera se llevó adelante un plan de APPCC para establecer cómo deben ser los procesos para que las fórmulas lácteas infantiles sean seguras para la alimentación de los lactantes.

\footnotetext{
Se puede entender que la idea de morbimortalidad significa aquellas enfermedades causantes de la muerte en determinadas poblaciones, espacios y tiempos.

${ }^{5}$ La nutrición enteral consiste en la administración de nutrientes de diversos tipos a través de una sonda.
} 


\section{METODOLOGIA}

El estudio se sustentó en base a una investigación proyectiva según Hurtado de Barrera (2010). A partir de un diagnóstico preciso de las necesidades del momento y de los procesos explicativos de las actividades del CEFLI, se llevaron adelante seis fases con el objetivo de implantar el SGSA: 1) recolección de información y diseño de base de datos, 2) análisis y descripción de los productos que integran la demanda que tuvo el CEFLI durante el periodo analizado, 3) descripción del proceso de elaboración de las fórmulas lácteas, 4) metodología de implementación del SGSA, 5) construcción y aplicación del SGSA, y 6) análisis e interpretación de los resultados. La investigación tuvo un diseño de campo, documental y contemporánea. La recolección de los datos se realizó in situ mediante la observación directa y entrevistas con el personal del CEFLI, para ver cómo se realizaban los procesos de preparación y elaboración de las fórmulas lácteas; además del análisis y revisión de la información documental existente en el lugar. El periodo de estudio de la documentación y registros se realizó durante 102 días en los meses de mayo a agosto del año 2016, en donde se analizó la demanda que tuvo el CEFLI. El análisis estadístico de los datos se realizó a partir de la prescripción de las fórmulas lácteas, a cada uno de los pacientes hospitalizados, realizadas por el profesional médico a cargo de cada sala del hospital y transcriptas a planillas de solicitud o pedido de fórmulas recibidas en el CEFLI. Estas prescripciones contenían datos sobre los tipos de fórmulas, volumen, número de dosis y vías de alimentación, para que se procediera a su preparación y provisión. Las planillas de solicitud o pedido conformaron un archivo y cargadas en una base de datos, obteniendo de esta manera la totalidad de la demanda diaria. Al final del periodo considerado, se pudo determinar la demanda agregada por sala, producto, dosis y formas de suministro, sus respectivos porcentuales y volúmenes totales por vía de administración. Se utilizó para esta determinación el software SPSS Versión 20, en sus módulos resúmenes de casos y tablas.

Para realizar el análisis del estado inicial del CEFLI respecto al cumplimiento de las Buenas Prácticas de Manufactura (BPM), se utilizó una lista de verificación adaptada a las características edilicias, de funcionamiento y complejidad del CEFLI, a partir del modelo propuesto por la Norma Técnica de Autorización Sanitaria para Servicios Dietéticos de Leche (SEDILE) y Central de Formulas Enterales (CEFE) del Ministerio de Salud de Chile (2012). De acuerdo con la misma, el CEFLI se considera como un centro de elaboración de fórmulas lácteas infantiles de alta complejidad.

Se evaluaron las dimensiones de: planta física, equipamiento de las áreas de trabajo, normas higiénico-sanitarias, recursos humanos, organización y administración.

La dimensión planta física se compuso de 54 variables o ítems de verificación, la dimensión equipamiento de áreas de trabajo por 53 variables distribuidas por áreas de trabajo, en la dimensión normas higiénico-sanitarias se incluyeron 43 variables, entre ellas las que se refieren a almacenamiento de materias primas, técnicas de limpieza y manipulación, medidas higiénicas del personal, elaboración, rotulado, envasado y distribución de fórmulas, control bacteriológico, si se aplica trazabilidad a la materia prima y fórmulas, entre otras. En cuanto a la dimensión de recursos humanos se consideraron 3 criterios relacionados a la presencia de nutricionistas. Por último, en la dimensión de organización y administración se tuvieron en cuenta 15 criterios que corresponden a la disponibilidad de un organigrama, manual de funciones del personal, si se aplica pauta de desempeño, existencia de un registro de stock de biberones, contenedores para alimentación enteral, fórmulas infantiles y de otros insumos. 
valor 1 si el CEFLI cumplía con la norma técnica y valor 0 si no la cumplía. La suma de todas las variables fue igual a 168, que represento el $100 \%$. Las variables obtenidas fueron cualitativas, dicotómicas (si cumple o no cumple) y para su descripción se utilizó la distribución de frecuencia en porcentajes.

Unidad de Consumo (UC): Se refiere a biberones o contenedores de enterales listos para su administración.

Unidad de Producción (UP): Se refiere a la cantidad de UC elaborados por día, para su administración dentro de las $24 \mathrm{~h}$, según el número de tomas que fue indicado por el médico tratante para cada paciente, de acuerdo con su edad, patología, y requerimiento energético.

Contenedor enteral: Recipiente estéril en el cual se envasa la fórmula para nutrición enteral y que se administra por sonda al paciente.

Fórmulas lácteas: Son aquellos productos constituidos por una mezcla definida de macro y micro nutrientes que se administran por vía digestiva. Con carácter general se entiende que se trata de fórmulas nutricionalmente completas, por lo que se pueden utilizar como única fuente nutricional.

Fórmulas lácteas en polvo: Son fórmulas para reconstituir que pueden contener bacterias vivas o sus esporas.

Formulas lácteos estériles: Son formulas producidas industrialmente, en forma líquida, libre de microorganismos y sus esporas.

Vía de nutrición enteral: Aporte de alimento con ingestión controlada de nutrientes por sonda.

Tiempo de colgado: Tiempo total durante el cual la fórmula de alimentación vía enteral se mantiene en el contenedor a temperatura ambiente mientras está siendo administrada al paciente. También incluye el período de tiempo durante el cual se interrumpe la administración, pero se mantiene el recipiente colgado.

Tiempo de conservación: Es el período comprendido desde la elaboración de fórmulas lácteas y su administración final al paciente. Este periodo debe transcurrir en condiciones de refrigeración caso contrario se debe consumir antes de las 2 horas posteriores a la elaboración.

Pedido o solicitudes: Son el total de las UC demandadas por cada sala.

Posteriormente, se aplicaron los principios del sistema APPCC propuesto por el Codex Alimentarius para identificar, evaluar y controlar los peligros significativos para la inocuidad de los procesos de almacenamiento, preparación, manipulación y distribución de las fórmulas lácteas. (FAO/OMS, 1969), (Figura 1). 




Figura 1. Principios del Sistema de Análisis de Peligros y Puntos Críticos de Control (APPCC) propuesto por el Codex Alimentarius Fuente: FAO/OMS CAC/RCP-1- 1969

Para identificar los Puntos Críticos de Control (PCC) indicados en el Análisis de Peligros, se utilizó el esquema conocido como Árbol para la Toma de Decisiones propuesto por el Codex Alimentarius. (FAO/OMS, 1969), (Figura 2).

El árbol de decisiones está conformado por cuatro preguntas identificadas con P1, P2, P3 y P4, las cuales se van respondiendo en forma secuencial para identificar las etapas del proceso que resultan críticas para el mantenimiento de la inocuidad del producto, estas quedaran señaladas como PCC.

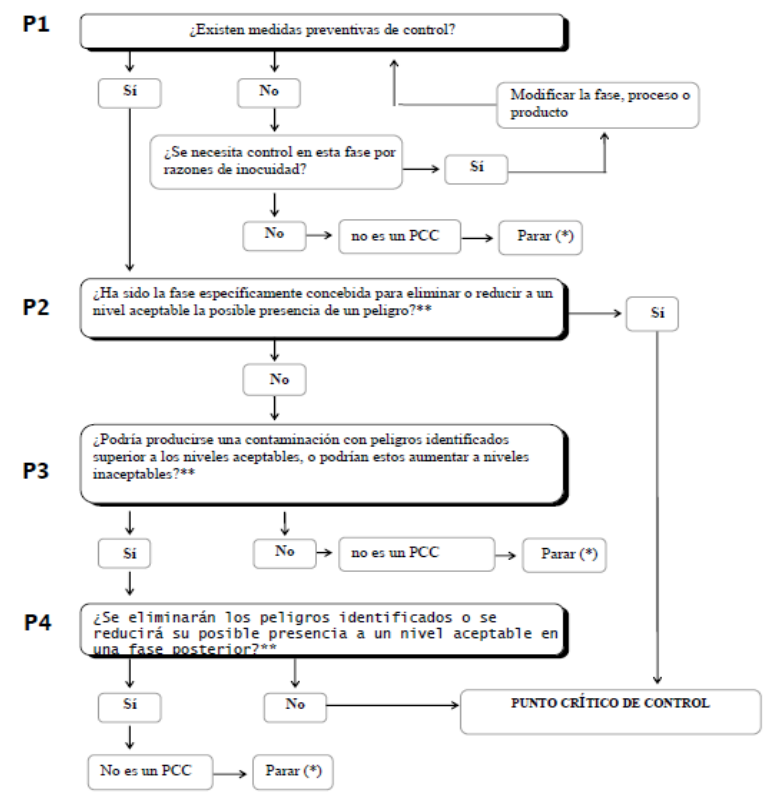

Figura 2. Árbol para la toma de decisiones 
$\left(^{*}\right)$ Pasar al siguiente peligro identificado en el proceso descrito

$\left.{ }^{(* *}\right)$ Los niveles aceptables e inaceptables necesitan ser definidos teniendo en cuenta los objetivos globales cuando se identifican los PCC del Plan de APPCC.

Fuente: FAO/OMS CAC/RCP1-1969

Para la realización del Plan APPCC del proceso de Elaboración de Fórmulas Lácteas en Polvo se tuvieron en cuenta, para cada PCC identificado, las relaciones existentes entre:

- Los peligros que controlar en cada PCC y las medidas que los controlan (medidas preventivas)

- Los límites críticos que indican si el proceso se encuentra bajo control y los procedimientos de vigilancia de dichos límites críticos.

- Las medidas a tomar si se superan los límites críticos (medidas correctivas) y los responsables de tomar estas medidas y los registros que demuestran su cumplimiento.

Finalmente, toda esta información se organizó en una tabla estandarizada por la norma de FAO/OMS (1969) convirtiéndose en el Plan de APPCC a implementarse.

\section{RESULTADOS}

En la tabla 1 se presenta la distribución de las salas desde donde proviene la demanda de fórmulas.

A su vez, las 11702 solicitudes de fórmulas infantiles preparados por el centro según los requerimientos de los profesionales médicos de cada sala se distribuyeron en 2917 pedidos de fórmulas infantiles liquidas estériles y 8785 pedidos de fórmulas infantiles en polvo reconstituidas.

Tabla 1. Demanda de fórmulas lácteas por tipo de sala y forma de administración

\begin{tabular}{|l|r|r|r|}
\hline & \multicolumn{3}{|c|}{ Vía administración } \\
\hline Salas & Biberón & Enteral & Total \\
\hline Bronquiolitis - temporal & 452 & 75 & 527 \\
\hline Cirugía & 75 & 111 & 186 \\
\hline Cirugía cardiovascular & 241 & 280 & 521 \\
\hline Infectología & 476 & 144 & 620 \\
\hline Leucemia & 57 & 42 & 99 \\
\hline Nefrología & 59 & 15 & 74 \\
\hline Neonatología & 1540 & 973 & 2513 \\
\hline Neumonología & 352 & 298 & 650 \\
\hline Nutrición y dietoterapia & 479 & 76 & 555 \\
\hline Quemados y plástica & 20 & 0 & 20 \\
\hline
\end{tabular}




\begin{tabular}{|l|r|r|r|}
\hline Terapia intensiva & 3 & 1631 & 1634 \\
\hline Terapia intensiva neo & 1176 & 307 & 1483 \\
\hline Terapia intermedia & 754 & 1121 & 1875 \\
\hline Terapia intermedia neo & 615 & 319 & 934 \\
\hline Trasplante de medula & 5 & 6 & 11 \\
\hline Total & $\mathbf{6 3 0 4}$ & $\mathbf{5 3 9 8}$ & $\mathbf{1 1 7 0 2}$ \\
\hline
\end{tabular}

En la tabla 2, se presenta la producción total en número de UC durante el período evaluado que se distribuyó en un $33 \%$ de UC por vía enteral y $67 \%$ de UC vía biberones. Esto represento una unidad de producción promedio (UP) de 219 UC enterales por día y 434 UC biberones por día que nos indica que el CEFLI produce más de 500 UC por día (653 UC por día). Este último dato se utilizó como parámetro para determinar la complejidad del Centro, según la Norma Técnica del SEDILE- CEFE del Ministerio de Salud de Chile (2012).

Tabla 2. UC por vía de administración durante el periodo de estudio

\begin{tabular}{|l|c|}
\hline Vía de administración & Nro. de UC \\
\hline Enterales & 22305 \\
\hline Biberones & 44311 \\
\hline Total & $\mathbf{6 6 6 1 6}$ \\
\hline
\end{tabular}

La producción expresada en litros de formula infantil, durante el período analizado, fue de 9262. El 20 \% (1852 L) correspondió al consumo de fórmulas líquidas estériles; mientras que el 80 \% (7410 L) restante correspondió a la elaboración de fórmulas en polvo. Esto

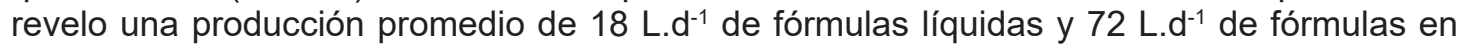
polvo. En la tabla 3 se muestra el desagregado de la producción de fórmulas infantiles del CEFLI expresado en litros. El centro produce $90 \mathrm{~L}$ diarios de fórmulas, de los cuales el $47 \%$ pertenecen a la preparación de las fórmulas en polvo en contenedores para nutrición enteral. Por otro lado, en términos de consumo diario estos resultados representaron un consumo

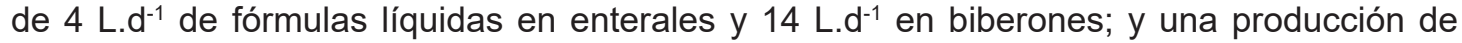
fórmulas en polvo de $30 \mathrm{~L} . \mathrm{d}^{-1}$ en biberones y $42 \mathrm{~L} . \mathrm{d}^{-1}$ en enterales.

Tabla 3. Cantidad por tipo de fórmula y vía de administración durante el período de estudio

\begin{tabular}{|l|c|c|}
\hline & $\begin{array}{c}\text { Litros de formula } \\
\text { (L) }\end{array}$ & \% \\
\hline Fórmulas líquidas en enterales & 418 & 4 \\
\hline Fórmulas líquidas en biberones & 1447 & 16 \\
\hline Fórmulas en polvo en biberones & 3083 & 33 \\
\hline Fórmulas en polvo en enterales & 4314 & 47 \\
\hline Total & $\mathbf{9 2 6 2}$ & $\mathbf{1 0 0}$ \\
\hline
\end{tabular}

Fuente: elaboración propia 2016

A continuación, en figura 3, se muestra el grado de cumplimiento del CEFLI con los requisitos de las BPM. Se observa que el menor porcentaje de cumplimiento $(20 \%)$ se corresponde con 
la dimensión organización y administración en la cual en sus desagregados se constató que el CEFLI no dispone de un organigrama, la inexistencia de información escrita sobre funciones del personal y procedimientos de actividades, la nula planificación mensual de fórmulas e insumos, la inexistencia de un registro de stock y la falta de evaluación del desempeño del personal y de reuniones programadas con el mismo por parte del coordinador del centro. Otra de las dimensiones que menor porcentaje de cumplimiento con las variables analizadas fue la de normas higiénico-sanitarias (31\%), destacándose falencia en el almacenamiento de materias primas, las técnicas de limpieza y manipulación, las medidas higiénicas del personal, disponibilidad de uniformes de trabajo y en la elaboración de fórmulas. En general, de todas las dimensiones estudiadas se alcanzó un porcentaje global del $49 \%$ de cumplimiento.

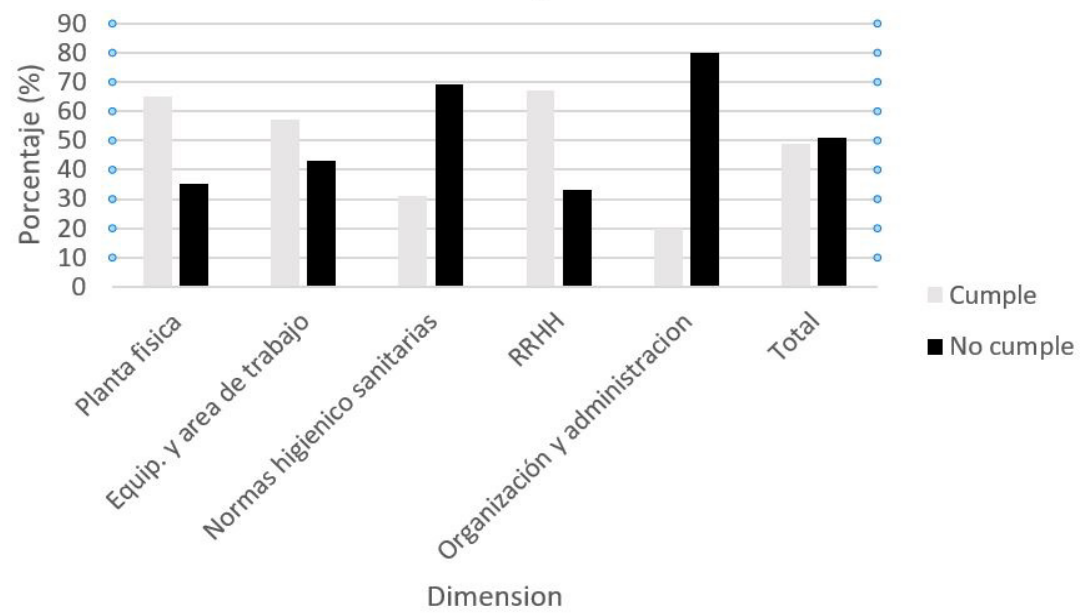

Figura 3. Porcentaje de Cumplimiento de BPM

Fuente: elaboración propia 2016

En las figuras 4 y 5 se puede observar el antes y el después de la denominada "sala sucia" en donde se realizaron mejoras relacionadas con el reemplazo de productos químicos de limpieza y jabón para el lavado de manos, por productos químicos aptos para uso en industria de alimentos, con certificación de SENASA dispuestos con dosificadores que garantizan el uso de los productos químicos a concentraciones adecuadas. Todo ello como acción correctiva de las no conformidades surgidas en la dimensión normas higiénicas sanitarias. Posteriormente se realizó una capacitación del personal encargado de la preparación de las fórmulas lácteas y del personal encargado de la limpieza del CEFLI en temas de Inocuidad, Manipulación de Alimentos y BPM. La sola inclusión de estos reemplazos permitió pasar del $69 \%$ al $37 \%$ de no conformidades (no cumple). 


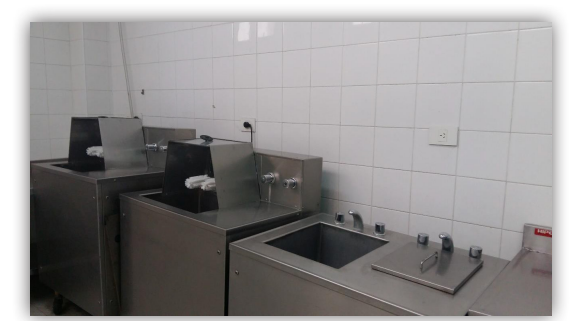

Figura 4. Área Sucia - Estado Inicial Fuente: CEFLI 2016

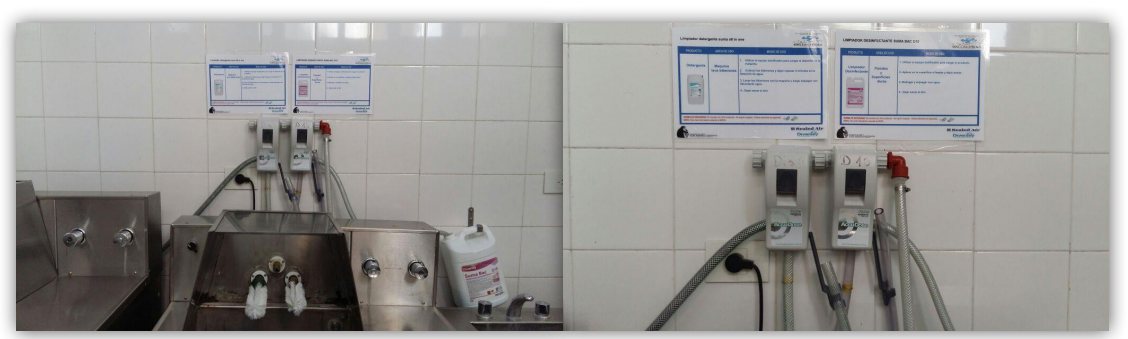

Figura 5. Área Sucia - instalación de dosificadores y reemplazo de productos químicos Fuente. CEFLI 2016

Se instaló un dosificador para el llenado de la máquina lavadora de biberones y piletas de lavado en el Área Sucia, además de la adquisición de detergente adecuado para el lavado de los biberones (Figura 5).

Cuando se analizó las no conformidades (no cumple) de la dimensión de equipamiento y áreas de trabajo se encontró que los equipos (2) de pasteurización terminal de fórmulas disponibles en el Centro no garantizan un ciclo de operación adecuado.

Dado que, en el análisis de la demanda, las fórmulas lácteas en polvo fueron las de mayor consumo en el centro y que del análisis de cumplimiento de BPM surge que las pasteurizadoras no se encontraban en condiciones operativas, es que se decidió llevar adelante el APPCC al proceso de elaboración de fórmulas lácteas infantiles en polvo para asegurar su calidad e inocuidad.

Se detallan a continuación las tareas realizadas siguiendo la secuencia lógica para la aplicación de APPCC (Figura 1):

- Formación de equipo APPCC: Multidisciplinario, conformado por:

- 2 Licenciadas en Nutrición, de la Unidad de Alimentación y Dietoterapia - CEFLI

- 1 Médica Nutricionista, del Servicio de Nutrición y Dietoterapia

- 1 Preparador de Fórmulas Lácteas Infantiles - Personal del CEFLI

- 1 Ingeniera en Alimentos - Agente externo al hospital

Determinación del ámbito de aplicación del Plan APPCC: circunscripto al proceso de elaboración de tomas para nutrición oral y enteral a partir de fórmulas lácteas infantiles en polvo.

- Descripción del producto y determinación del uso previsto: 
Tabla 4. Descripción del producto

\begin{tabular}{|l|l|}
\hline Producto & $\begin{array}{l}\text { UC para alimentación oral (biberones) y para alimentación enteral } \\
\text { (enterales) preparadas con fórmulas lácteas infantiles en polvo } \\
\text { reconstituidas. }\end{array}$ \\
\hline Uso previsto & $\begin{array}{l}\text { La administración de los biberones se realiza según horarios } \\
\text { fisiológicos de ingesta } \\
\text { La administración de enterales se realiza por sonda nasogástrica, } \\
\text { naso duodenal, naso yeyunal o por sonda de gastrostomía por } \\
\text { infusión a velocidad constante durante las } 24 \text { h o solo durante la } \\
\text { noche }(12 \text { h) }\end{array}$ \\
\hline $\begin{array}{l}\text { Condiciones de } \\
\text { almacenamiento }\end{array}$ & $\begin{array}{l}\text { El producto debe mantenerse en condiciones de refrigeración, a } \\
\text { temperaturas entre } 0-5^{\circ} \mathrm{C}\end{array}$ \\
\hline Vida útil & $\begin{array}{l}\text { Toda UC refrigerada que no haya sido consumida en un plazo de } \\
24 \mathrm{~h}, \text { debe ser desechada. } \\
\text { Las UC para administración enteral no pueden permanecer } \\
\text { colgadas a temperatura ambiente por más de } 4 \mathrm{~h} \text {. }\end{array}$ \\
\hline
\end{tabular}

Fuente: elaboración propia 2016

- Elaboración del diagrama de flujo y confirmación in situ: Por imposibilidad técnica para controlar la etapa de pasteurización al momento de implementar el sistema APPCC, se decidió modificar el proceso de elaboración de biberones y enterales con fórmulas lácteas infantiles en polvo. En la figura 6 , se muestran las fases operaciales del proceso propuesto que se corresponde con el proceso real.

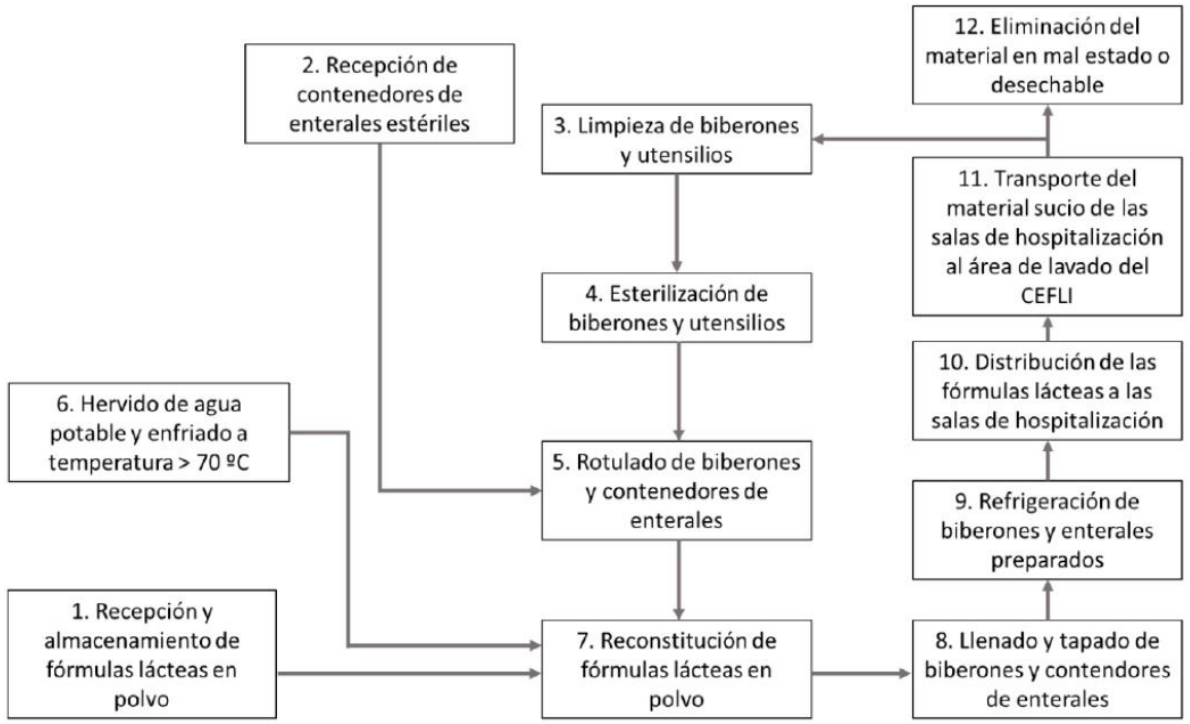

Figura 6. Diagrama de Flujo del Proceso de Elaboración de Biberones y Enterales a partir de Fórmulas Lácteas Infantiles en Polvo

Fuente: CEFLI 2016. 
Principio 1: Análisis de Peligros: se identificaron y registraron, en cada etapa, los peligros potenciales para la inocuidad del producto. Una vez identificados los peligros físicos, químicos y/o biológicos asociados a cada etapa del proceso productivo, se procedió a su evaluación para determinar si su eliminación o reducción puede ser llevada por debajo de los niveles aceptables para conseguir un producto inocuo. En la figura 7 se detalla el Análisis de Peligros por cada etapa del proceso, identificando al agente potencial de riesgo, su evaluación, intensidad, fundamento por el cual es así considerado y la existencia de medidas preventivas de control.

\begin{tabular}{|c|c|c|c|c|c|c|c|c|}
\hline \multirow{2}{*}{ Etapa } & \multirow{2}{*}{ Peligros Asociados } & \multicolumn{2}{|c|}{$\begin{array}{l}\text { Evaluación } \\
\text { de Riesgos }\end{array}$} & \multirow{2}{*}{ Riesgo } & \multirow{2}{*}{ Fundamento } & \multirow{2}{*}{$\begin{array}{l}\text { ¿Existen medidas } \\
\text { preventivas de control } \\
\text { que pueden aplicarse? }\end{array}$} & \multirow{2}{*}{$\begin{array}{l}\text { ¿Es } \\
\text { esta } \\
\text { etapa } \\
\text { un } \\
\text { PCC? }\end{array}$} & \multirow{2}{*}{$\begin{array}{l}\text { No } \\
\text { de } \\
\text { PCC }\end{array}$} \\
\hline & & $\mathbf{P}$ & G & & & & & \\
\hline $\begin{array}{c}\text { Recepción y } \\
\text { Almacenamiento de } \\
\text { fórmulas lácteas en } \\
\text { polvo }\end{array}$ & $\begin{array}{l}\text { Biológico: proliferación de } \\
\text { microorganismos patógenos } \\
\text { (E. sakazakii y Salmonella) } \\
\text { potencialmente presentes en } \\
\text { las fórmulas en polvo }\end{array}$ & 1 & 5 & Moderado & $\begin{array}{c}\text { E. sakazakii es un patógeno } \\
\text { causante de meningitis y } \\
\text { bacteremia en el lactante; no } \\
\text { obstante estos patógenos no } \\
\text { son capaces de multiplicarse en } \\
\text { las fórmulas lácteas en polvo sin } \\
\text { reconstituir }\end{array}$ & 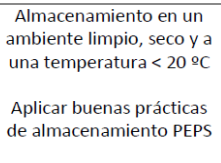 & NO & \\
\hline $\begin{array}{l}\text { Recepción de } \\
\text { contenedores de } \\
\text { enterales estériles }\end{array}$ & Ninguno & & & & $\begin{array}{c}\text { Los contenedores se } \\
\text { recepcionan en envase estéril, } \\
\text { con toda la información legal } \\
\text { correspondiente y cinta testigo } \\
\text { de control de exposición al } \\
\text { vapor } \\
\end{array}$ & $\begin{array}{c}\text { Aplicar buenas prácticas } \\
\text { de almacenamiento PEPS } \\
\text { Aplicar BPM, POES }\end{array}$ & NO & \\
\hline \multirow[t]{2}{*}{$\begin{array}{c}\text { Limpieza de biberones } \\
\text { y utensilios }\end{array}$} & $\begin{array}{l}\text { Biológico: proliferación de } \\
\text { microrganismos patógenos } \\
\text { y/o formación de esperas en } \\
\text { restos de fórmula láctea }\end{array}$ & 1 & 5 & Moderado & $\begin{array}{c}\text { Los restos de fórmula láctea son } \\
\text { el alimento óptimo para la } \\
\text { proliferación de organismos } \\
\text { patógenos }\end{array}$ & $\begin{array}{c}\text { Aplicar POES para el } \\
\text { lavado de biberones y } \\
\text { utensilios } \\
\text { Utilizar productos } \\
\text { químicos certificados, } \\
\text { aptos uso alimenticio }\end{array}$ & NO & \\
\hline & $\begin{array}{l}\text { Químico: persistencia de } \\
\text { restos de fórmula láctea y/o } \\
\text { productos químicos de } \\
\text { limpieza }\end{array}$ & 1 & 5 & Moderado & $\begin{array}{c}\text { Los productos químicos y restos } \\
\text { de fórmula láctea pueden } \\
\text { causar una intoxicación química } \\
\text { en el lactante }\end{array}$ & $\begin{array}{c}\text { Aplicar POES para el } \\
\text { lavado de biberones y } \\
\text { utensilios }\end{array}$ & NO & \\
\hline \multirow{3}{*}{ Etapa } & \multirow{3}{*}{ Peligros Asociados } & \multicolumn{2}{|c|}{$\begin{array}{l}\text { Evaluación } \\
\text { de Riesgos }\end{array}$} & \multirow[b]{2}{*}{ Riesgo } & \multirow[b]{2}{*}{ Fundamento } & \multirow{2}{*}{$\begin{array}{l}\text { ¿Existen medidas } \\
\text { preventivas de control } \\
\text { que pueden aplicarse? }\end{array}$} & \multirow{2}{*}{$\begin{array}{l}\text { ¿Es } \\
\text { esta } \\
\text { etapa } \\
\text { un } \\
\text { PCC? }\end{array}$} & \multirow{2}{*}{$\begin{array}{l}\text { № } \\
\text { de } \\
\text { PCC }\end{array}$} \\
\hline & & $\mathbf{P}$ & G & & & & & \\
\hline & & & & & & $\begin{array}{l}\text { Utilizar productos } \\
\text { químicos certificados, } \\
\text { aptos uso alimenticio }\end{array}$ & & \\
\hline $\begin{array}{c}\text { Esterilización de } \\
\text { biberones y utensilios }\end{array}$ & $\begin{array}{l}\text { Biológico: persistencia de } \\
\text { esperas potencialmente } \\
\text { patógenas }\end{array}$ & 5 & 5 & Crítico & $\begin{array}{c}\text { Pueden ocurrir fallas en proceso } \\
\text { de esterilización }\end{array}$ & $\begin{array}{c}\text { Utilizar cintas testigos de } \\
\text { control de exposición al } \\
\text { vapor } \\
\text { Control de los datos del } \\
\text { proceso registrados en } \\
\text { papel que entrega el } \\
\text { equipo }\end{array}$ & SI & 1 \\
\hline \multirow[b]{2}{*}{$\begin{array}{l}\text { Rotulado de } \\
\text { biberones y } \\
\text { contenedores de } \\
\text { enterales }\end{array}$} & $\begin{array}{l}\text { Biológico: contaminación con } \\
\text { microorganismos patógenos }\end{array}$ & 1 & 5 & Moderado & $\begin{array}{l}\text { La incorrecta manipulación } \\
\text { puede contaminar el producto }\end{array}$ & Se aplican las BPM & NO & \\
\hline & $\begin{array}{l}\text { Químico: administración de } \\
\text { fórmula láctea no apta para } \\
\text { el paciente por incorrecto } \\
\text { etiquetado }\end{array}$ & 1 & 5 & Moderado & $\begin{array}{l}\text { Puede ocurrir error humano } \\
\text { durante el rotulado }\end{array}$ & $\begin{array}{c}\text { Aplicar protocolo para el } \\
\text { rotulado de biberones y } \\
\text { enterales } \\
\text { El personal de salud } \\
\text { encargado de la } \\
\text { administración de la toma } \\
\text { debe corroborar que el } \\
\text { rotulado es correcto y } \\
\text { coincide con la indicación } \\
\text { del paciente, previo a su } \\
\text { administración }\end{array}$ & NO & \\
\hline
\end{tabular}




\begin{tabular}{|c|c|c|c|c|c|c|c|c|}
\hline \multirow{2}{*}{ Etapa } & \multirow{2}{*}{ Peligros Asociados } & \multicolumn{2}{|c|}{$\begin{array}{l}\text { Evaluación } \\
\text { de Riesgos } \\
\end{array}$} & \multirow{2}{*}{ Riesgo } & \multirow{2}{*}{ Fundamento } & \multirow{2}{*}{$\begin{array}{l}\text { ¿Existen medidas } \\
\text { preventivas de control } \\
\text { que pueden aplicarse? }\end{array}$} & \multirow{2}{*}{$\begin{array}{l}\text { ¿Es } \\
\text { esta } \\
\text { etapa } \\
\text { un } \\
\text { PCC? }\end{array}$} & \multirow{2}{*}{$\begin{array}{l}\text { № } \\
\text { de } \\
\text { PCC }\end{array}$} \\
\hline & & $P$ & $\mathbf{G}$ & & & & & \\
\hline $\begin{array}{l}\text { Hervido del agua } \\
\text { potable y enfriado a } \\
\text { temperatura }>70 \stackrel{\circ}{ } \mathrm{C}\end{array}$ & $\begin{array}{l}\text { Biológico: proliferación de } \\
\text { microorganismos patógenos } \\
\text { presentes en el agua de } \\
\text { reconstitución }\end{array}$ & 5 & 5 & Crítico & $\begin{array}{l}\text { Los tanques y cañerías de } \\
\text { suministro de agua potable del } \\
\text { Hospital pueden estar } \\
\text { contaminadas con } \\
\text { microorganismos patógenos }\end{array}$ & $\begin{array}{c}\text { Hervir el agua potable en } \\
\text { el momento de realizar la } \\
\text { reconstitución y no dejar } \\
\text { enfriar por debajo de los } \\
70^{\circ} \mathrm{C} \\
\\
\text { Análisis microbiológicos } \\
\text { periódicos según } \\
\text { establece la autoridad } \\
\text { competente }\end{array}$ & SI & 2 \\
\hline \multirow[t]{2}{*}{$\begin{array}{c}\text { Reconstitución de } \\
\text { fórmulas lácteas en } \\
\text { polvo }\end{array}$} & $\begin{array}{l}\text { Biológico: proliferación de } \\
\text { microorganismos patógenos } \\
\text { potencialmente presentes en } \\
\text { la fórmulas lácteas en polvo } \\
\text { (E. sakazakii y otras } \\
\text { enterobacterias), y la } \\
\text { contaminación externa con } \\
\text { otros microorganismos } \\
\text { patógenos }\end{array}$ & 3 & 5 & Mayor & $\begin{array}{l}\text { Las fórmulas lácteas en polvo } \\
\text { reconstituidas ofrecen un medio } \\
\text { idóneo para la proliferación de } \\
\text { organismos patógenos }\end{array}$ & $\begin{array}{c}\text { Reconstituir las fórmulas } \\
\text { lácteas en polvo con agua } \\
\text { potable hervida y enfriada } \\
\text { a una temperatura }>70 \circ \mathrm{C} \\
\text { Mantener la temperatura } \\
\text { de la sala de elaboración } \\
\text { (Área Limpia) a } \\
\text { temperatura }<20^{\circ} \mathrm{C} \\
\text { Aplicar BPM }\end{array}$ & SI & 3 \\
\hline & $\begin{array}{l}\text { Físico: contaminación física } \\
\text { (trozos de envases, pelos, } \\
\text { anillos, curitas, etc) }\end{array}$ & 1 & 5 & Moderado & $\begin{array}{l}\text { La incorrecta manipulación } \\
\text { puede contaminar el producto }\end{array}$ & Aplicar BPM & NO & \\
\hline \multirow{3}{*}{ Etapa } & \multirow{2}{*}{ Peligros Asociados } & \multicolumn{2}{|c|}{$\begin{array}{l}\text { Evaluación } \\
\text { de Riesgos }\end{array}$} & \multirow{2}{*}{ Riesgo } & \multirow{2}{*}{ Fundamento } & \multirow{2}{*}{$\begin{array}{l}\text { ¿Existen medidas } \\
\text { preventivas de control } \\
\text { que pueden aplicarse? }\end{array}$} & \multirow{2}{*}{$\begin{array}{l}\text { ¿Es } \\
\text { esta } \\
\text { etapa } \\
\text { un } \\
\text { PCC? }\end{array}$} & \multirow{2}{*}{$\begin{array}{l}\text { № } \\
\text { de } \\
\text { PCC }\end{array}$} \\
\hline & & $\mathbf{P}$ & G & & & & & \\
\hline & $\begin{array}{l}\text { Químico: contaminación } \\
\text { química (contaminación } \\
\text { cruzada de fórmulas, } \\
\text { maquillaje, perfume, etc) }\end{array}$ & 1 & 5 & Moderado & $\begin{array}{l}\text { La incorrecta manipulación } \\
\text { puede contaminar el producto }\end{array}$ & Aplicar BPM & NO & \\
\hline \multirow[t]{3}{*}{$\begin{array}{l}\text { Llenado y tapado de } \\
\text { los contenedores de } \\
\text { enterales con fórmula } \\
\text { láctea }\end{array}$} & $\begin{array}{l}\text { Biológico: contaminación } \\
\text { extrínseca con } \\
\text { microorganismos patógenos } \\
\text { y proliferación de } \\
\text { microorganismos }\end{array}$ & 3 & 5 & Mayor & $\begin{array}{l}\text { La incorrecta manipulación } \\
\text { puede contaminar el producto y } \\
\text { favorecer el desarrollo de } \\
\text { microorganismos patógenos }\end{array}$ & \begin{tabular}{|c} 
Llenar los biberones y \\
enterales inmediatamente \\
después de su \\
reconstitución \\
Mantener la temperatura \\
de la sala de elaboración \\
(Área Limpia) a \\
temperatura < $20 \circ \mathrm{C}$ \\
Aplicar BPM \\
\end{tabular} & SI & 4 \\
\hline & $\begin{array}{l}\text { Químico: contaminación } \\
\text { química }\end{array}$ & 1 & 5 & Moderado & $\begin{array}{l}\text { La incorrecta manipulación } \\
\text { puede contaminar el producto }\end{array}$ & Aplicar BPM & NO & \\
\hline & Físico: contaminación física & 1 & 5 & Moderado & $\begin{array}{l}\text { La incorrecta manipulación } \\
\text { puede contaminar el producto }\end{array}$ & Aplicar BPM & NO & \\
\hline $\begin{array}{c}\text { Refrigeración de } \\
\text { biberones y enterales } \\
\text { con fórmula láctea }\end{array}$ & $\begin{array}{l}\text { Biológico: proliferación de } \\
\text { microorganismos patógenos }\end{array}$ & 3 & 5 & Mayor & $\begin{array}{c}\text { La proliferación de } \\
\text { microorganismos patógenos } \\
\text { puede casar enfermedad grave } \\
\text { en el lactante, discapacidad o } \\
\text { incluso la muerte } \\
\end{array}$ & $\begin{array}{c}\text { Refrigeración inmediata } \\
\text { de las tomas elaboradas a } \\
\text { temperatura }<5 \circ \mathrm{C}\end{array}$ & SI & 5 \\
\hline \multirow{2}{*}{ Etapa } & \multirow{2}{*}{ Peligros Asociados } & \multicolumn{2}{|c|}{$\begin{array}{l}\text { Evaluación } \\
\text { de Riesgos }\end{array}$} & \multirow{2}{*}{ Riesgo } & \multirow{2}{*}{ Fundamento } & \multirow{2}{*}{$\begin{array}{l}\text { ¿Existen medidas } \\
\text { preventivas de control } \\
\text { que pueden aplicarse? }\end{array}$} & \multirow{2}{*}{$\begin{array}{l}\text { ¿Es } \\
\text { esta } \\
\text { etapa } \\
\text { un } \\
\text { PCC? }\end{array}$} & \multirow{2}{*}{$\begin{array}{l}\text { № } \\
\text { de } \\
\text { PCC }\end{array}$} \\
\hline & & $\mathbf{P}$ & G & & & & & \\
\hline $\begin{array}{c}\text { Distribución de las } \\
\text { tomas a las salas de } \\
\text { hospitalización }\end{array}$ & $\begin{array}{l}\text { Biológico: proliferación de } \\
\text { microorganismos patógenos }\end{array}$ & 3 & 5 & Mayor & $\begin{array}{l}\text { La proliferación de } \\
\text { microorganismos patógenos } \\
\text { puede casar enfermedad grave } \\
\text { en el lactante, discapacidad o } \\
\text { incluso la muerte }\end{array}$ & $\begin{array}{c}\begin{array}{c}\text { Retirar las tomas de las } \\
\text { heladeras } \\
\text { inmediatamente antes del } \\
\text { reparto. } \\
\text { Aplicar BPM }\end{array} \\
\end{array}$ & SI & 6 \\
\hline $\begin{array}{c}\text { Transporte del } \\
\text { material sucio de las } \\
\text { salas de } \\
\text { hospitalización al Área } \\
\text { Sucia del CEFLI } \\
\end{array}$ & Ninguna & & & & $\begin{array}{l}\text { El material debe ser lavado y } \\
\text { esterilizado para su reutilización }\end{array}$ & & NO & \\
\hline $\begin{array}{l}\text { Eliminación del } \\
\text { material en mal } \\
\text { estado o desechable }\end{array}$ & $\begin{array}{l}\text { Físico: lastimaduras causadas } \\
\text { por la rotura del biberón }\end{array}$ & 1 & 5 & Moderado & $\begin{array}{c}\text { Puede circular material en mal y } \\
\text { no ser evidenciado }\end{array}$ & $\begin{array}{l}\text { Aplicar protocolo de retiro } \\
\text { del material en mal estado }\end{array}$ & NO & \\
\hline
\end{tabular}

\section{P: probabilidad de ocurrencia}

G: gravedad

PCC: punto crítico de control 
Principio 2: De la aplicación del árbol para la Toma de Decisiones (Figura 2) se identificaron los siguientes PCC que se resumen en la tabla 5.

Tabla 5. PCC identificados en el proceso

\begin{tabular}{|l|c|}
\hline Etapa del Proceso & PCC \\
\hline Esterilización de biberones y utensilios & $\mathrm{SI}$ \\
\hline Hervido del agua potable y enfriado a temperatura $>70^{\circ} \mathrm{C}$ & $\mathrm{SI}$ \\
\hline Reconstitución de fórmulas lácteas en polvo & $\mathrm{SI}$ \\
\hline $\begin{array}{l}\text { Llenado y tapado de los contenedores de enterales con fórmula } \\
\text { láctea }\end{array}$ & $\mathrm{SI}$ \\
\hline Refrigeración de biberones y enterales con fórmula láctea & $\mathrm{SI}$ \\
\hline Distribución de las tomas a las salas de hospitalización & $\mathrm{SI}$ \\
\hline
\end{tabular}

Fuente: elaboración propia 2016

En este apartado se verifico que la etapa de hervido del agua potable y reconstitución de fórmulas lácteas son un PCC debido a la inexistencia del equipamiento para llevar a cabo una pasteurización terminal de las fórmulas, que minimice o reduzca a niveles aceptables los peligros de contaminación microbiológica. Dada esta circunstancia, se decidió que el agua de reconstitución no debe enfriarse por debajo de los $70^{\circ} \mathrm{C}$ una vez que alcanzo el punto de ebullición.

Seguidamente, se muestra el plan APPCC (Figura 8) elaborado sobre los PCC identificados en tabla 5. En este plan se presentó la etapa del proceso identificada como critica, el o los peligros asociados a la misma, los criterios que diferencian la aceptabilidad o inaceptabilidad del proceso en una determinada fase, el sistema de monitoreo de los limites críticos, las medidas correctivas que hay que realizar cuando los resultados del monitoreo de los PCC indican pérdida en el control del proceso llevado adelante, los registros utilizados y procedimientos de verificación.

\begin{tabular}{|c|c|c|c|c|c|c|c|c|c|c|}
\hline \multirow{2}{*}{ 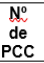 } & \multirow{2}{*}{ Etapa } & \multirow{2}{*}{ Peligro } & \multirow{2}{*}{ Limite critico } & \multicolumn{4}{|c|}{ Monitoreo } & \multirow{2}{*}{$\begin{array}{c}\text { Medidas } \\
\text { correctivas }\end{array}$} & \multirow{2}{*}{ Registros } & \multirow{2}{*}{$\begin{array}{l}\text { Verificación / } \\
\text { Responsable }\end{array}$} \\
\hline & & & & ¿Que? & ¿Cómo? & Frecuencia & ¿Quién? & & & \\
\hline 1 & $\begin{array}{c}\text { Esterilización } \\
\text { de biberones y } \\
\text { utensilios }\end{array}$ & $\begin{array}{l}\text { Biológico: } \\
\text { persistencia de } \\
\text { esporas } \\
\text { potencialmente } \\
\text { patógenas }\end{array}$ & $\begin{array}{c}\text { Medida de } \\
\text { temperatura y } \\
\text { tiempo d } \\
\text { esterilización } \\
121^{\circ} \mathrm{C} \times 20 \\
\text { minutos } \\
\\
\text { No viraje de la } \\
\text { cinta testigo } \\
\text { para vapor }\end{array}$ & $\begin{array}{l}\text { Temperatura } \\
\text { y tiempo de } \\
\text { esterilización }\end{array}$ & $\begin{array}{l}\text { Monitoreando } \\
\text { el registro de } \\
\text { datos del } \\
\text { proceso que } \\
\text { imprime el } \\
\text { autoclave } \\
\text { Control de } \\
\text { viraje de la } \\
\text { cinta testigo } \\
\text { para vapor del } \\
\text { amarillo claro } \\
\text { al color café }\end{array}$ & $\begin{array}{c}\text { En cada ciclo } \\
\text { de } \\
\text { esterilización }\end{array}$ & $\begin{array}{l}\text { Personal del } \\
\text { CEFLI que } \\
\text { realizo la } \\
\text { tarea de } \\
\text { limpieza y } \\
\text { esterilización }\end{array}$ & $\begin{array}{c}\text { Re-esterilizar el } \\
\text { material en ntro } \\
\underline{\text { autoclave }} \\
\text { Dar aviso al } \\
\text { servicio de } \\
\text { Mantenimiento }\end{array}$ & $\begin{array}{c}\text { Registro de } \\
\text { datos del } \\
\text { proceso que } \\
\text { imprime ell } \\
\text { autoclave } \\
\text { Registro de } \\
\text { viraje conforme } \\
\text { de la cinta } \\
\text { testigo para } \\
\text { vapor }\end{array}$ & $\begin{array}{l}\text { Responsable: } \\
\text { Nutricionista del } \\
\text { CEFLI } \\
\text { Revisión diaria } \\
\text { de todos los } \\
\text { registros } \\
\text { Control } \\
\text { microbiológico } \\
\text { (semanal) del } \\
\text { proceso, } \\
\text { supervisado por } \\
\text { personal de } \\
\text { Bacteriología }\end{array}$ \\
\hline 2 & $\begin{array}{l}\text { Hervido de } \\
\text { agua potable y } \\
\text { enfriado a } \\
\text { temperatura } \\
\geq 70^{\circ} \mathrm{C}\end{array}$ & $\begin{array}{c}\text { Biológico: } \\
\text { proliferación de } \\
\text { microorganismos } \\
\text { patógenos } \\
\text { presentes en el } \\
\text { agua de } \\
\text { reconstitución }\end{array}$ & $\begin{array}{l}\text { Hervor fuerte, } \\
\text { durante } 5 \\
\text { minutos } \\
\\
\text { Temperatura } \\
\text { mínima de } \\
\text { enfriado } 70^{\circ} \mathrm{C}\end{array}$ & $\begin{array}{l}\text { Tiempo de } \\
\text { hervor } \\
\text { Temperatura } \\
\text { del agua } \\
\text { potable } \\
\text { hervida }\end{array}$ & $\begin{array}{c}\text { Controlando } \\
\text { el tiempo de } \\
\text { hervor } \\
\text { Registrando } \\
\text { la } \\
\text { temperatura } \\
\text { del agua } \\
\text { potable } \\
\text { hervida }\end{array}$ & Continuo & $\begin{array}{l}\text { Preparador } \\
\text { del CEFLI }\end{array}$ & $\begin{array}{c}\text { Llevar } \\
\text { nuevamente a } \\
\text { hervor }\end{array}$ & $\begin{array}{l}\text { Registro de } \\
\text { temperatura } \\
\text { del agua de } \\
\text { reconstitución }\end{array}$ & $\begin{array}{l}\text { Responsable: } \\
\text { Nutricionista del } \\
\text { CEFLI } \\
\text { Revisión diaria } \\
\text { de los registros }\end{array}$ \\
\hline
\end{tabular}




\begin{tabular}{|c|c|c|c|c|c|c|c|c|c|c|}
\hline \multirow{2}{*}{$\begin{array}{l}\mathrm{N}^{0} \\
\mathrm{de} \\
\mathrm{PCC}\end{array}$} & \multirow{2}{*}{ Etapa } & \multirow{2}{*}{ Peligro } & \multirow{2}{*}{ Limite critico } & \multicolumn{4}{|c|}{ Monitoreo } & \multirow{2}{*}{$\begin{array}{l}\text { Medidas } \\
\text { correctivas }\end{array}$} & \multirow{2}{*}{ Registros } & \multirow{2}{*}{$\begin{array}{l}\text { Verificación / } \\
\text { Responsable }\end{array}$} \\
\hline & & & & ¿Que? & ¿Cómo? & Frecuencia & ¿Quién? & & & \\
\hline 3 & $\begin{array}{l}\text { Reconstitución } \\
\text { de fórmulas } \\
\text { lácteas en } \\
\text { polvo }\end{array}$ & $\begin{array}{c}\text { Biológico: } \\
\text { proliferación de } \\
\text { microorganismos } \\
\text { patógenos } \\
\text { potencialmente } \\
\text { presentes en las } \\
\text { fórmulas lácteas en } \\
\text { polvo (EvSakazakakii y } \\
\text { otras } \\
\text { enterobacterias), y } \\
\text { la contaminación } \\
\text { externa con otros } \\
\text { microorganismos } \\
\text { patógenos }\end{array}$ & $\begin{array}{c}\text { Temperatura } \\
\text { del agua de } \\
\text { reconstitución } \\
\geq 70^{\circ} \mathrm{C} \\
\\
\\
\begin{array}{c}\text { Temperatura } \\
\text { del Área limpia } \\
<22^{\circ} \mathrm{C}\end{array}\end{array}$ & $\begin{array}{l}\text { Temperatura } \\
\text { del agua } \\
\text { antes de } \\
\text { reconstituir la } \\
\text { formula láctea } \\
\\
\\
\text { Temperatura } \\
\text { del ambiente } \\
\text { de producción }\end{array}$ & $\begin{array}{c}\text { Registrando } \\
\text { la } \\
\text { temperatura } \\
\text { del agua } \\
\text { potable } \\
\text { hervida } \\
\\
\\
\\
\text { Registrando } \\
\text { la } \\
\text { temperatura } \\
\text { del Área }\end{array}$ & $\begin{array}{l}\text { Cada vez que } \\
\text { se prepara } \\
\text { una formula } \\
\text { láctea } \\
\\
\text { En cada turno } \\
\text { de producción }\end{array}$ & $\begin{array}{l}\text { Preparador } \\
\text { del CEFLI }\end{array}$ & $\begin{array}{l}\text { Llevar } \\
\text { nuevamente a } \\
\text { hervor }\end{array}$ & $\begin{array}{c}\text { Registro de } \\
\text { temperatura } \\
\text { del agua de } \\
\text { reconstitución } \\
\\
\text { Registro de } \\
\text { temperatura } \\
\text { del Área limpia }\end{array}$ & $\begin{array}{l}\text { Responsable: } \\
\begin{array}{c}\text { Nutricionista del } \\
\text { CEFLI }\end{array} \\
\text { Revisión diaria } \\
\text { de los registros }\end{array}$ \\
\hline 4 & $\begin{array}{l}\text { Llenado y } \\
\text { tapado de los } \\
\text { biberones y } \\
\text { contenedores } \\
\text { de enterales } \\
\text { con formula } \\
\text { láctea }\end{array}$ & $\begin{array}{l}\text { Biológico: } \\
\text { contaminación } \\
\text { extrínseca con } \\
\text { microorganismos } \\
\text { patógenos y } \\
\text { proliferación de } \\
\text { microorganismos }\end{array}$ & $\begin{array}{l}\text { Temperatura } \\
\text { del Área limpia } \\
<22^{\circ} \mathrm{C}\end{array}$ & $\begin{array}{c}\text { Temperatura } \\
\text { del ambiente } \\
\text { de producción }\end{array}$ & $\begin{array}{c}\text { Registrando } \\
\text { la } \\
\text { temperatura } \\
\text { del Área }\end{array}$ & $\begin{array}{l}\text { En cada turno } \\
\text { de producción }\end{array}$ & $\begin{array}{l}\text { Preparador } \\
\text { del CEFLI }\end{array}$ & $\begin{array}{c}\text { Encender el aire } \\
\text { acondicionado }\end{array}$ & $\begin{array}{c}\text { Registro de } \\
\text { temperatura } \\
\text { del Área limpia }\end{array}$ & $\begin{array}{c}\text { Responsable: } \\
\text { Nutricionista del } \\
\text { CEFLI } \\
\text { Revisión diaria } \\
\text { de los registros } \\
\text { Control } \\
\text { microbiológico } \\
\text { (semanal) del } \\
\text { proceso, } \\
\text { supervisado por } \\
\text { personal de } \\
\text { Bacteriología }\end{array}$ \\
\hline \multirow{2}{*}{$\begin{array}{c}\mathrm{N}^{0} \\
\mathrm{de} \\
\mathrm{PCC}\end{array}$} & \multirow{2}{*}{ Etapa } & \multirow{2}{*}{ Peligro } & \multirow{2}{*}{ Limite critico } & \multicolumn{4}{|c|}{ Monitoreo } & \multirow{2}{*}{$\begin{array}{l}\text { Medidas } \\
\text { correctivas }\end{array}$} & \multirow{2}{*}{ Registros } & \multirow{2}{*}{$\begin{array}{l}\text { Verificación / } \\
\text { Responsable }\end{array}$} \\
\hline & & & & ¿Que? & ¿Cómo? & Frecuencia & ¿Quién? & & & \\
\hline 5 & $\begin{array}{l}\text { Refrigeración } \\
\text { de biberones y } \\
\text { enterales con } \\
\text { formula láctea }\end{array}$ & $\begin{array}{l}\text { Biológico: } \\
\text { proliferación de } \\
\text { macroorganismos } \\
\text { patógenos }\end{array}$ & $\begin{array}{c}\text { Refrigeración a } \\
\text { temperatura } \\
<5^{\circ} \mathrm{C} \text {, por un } \\
\text { tiempo máximo } \\
\text { de } 24 \mathrm{~h}\end{array}$ & $\begin{array}{l}\text { Temperatura } \\
\text { de heladeras }\end{array}$ & $\begin{array}{c}\text { Registrando } \\
\text { la } \\
\text { temperatura } \\
\text { de heladeras } \\
\text { y controlando } \\
\text { que no } \\
\text { queden en las } \\
\text { mismas } \\
\text { tomas del día } \\
\text { anterior }\end{array}$ & $\begin{array}{l}\text { En cada turno } \\
\text { de producción }\end{array}$ & $\begin{array}{l}\text { Preparador } \\
\text { del CEFLI }\end{array}$ & $\begin{array}{l}\text { Desechar las } \\
\text { tomas }\end{array}$ & $\begin{array}{l}\text { Registro de } \\
\text { temperaturas } \\
\text { de heladeras }\end{array}$ & $\begin{array}{c}\text { Responsable: } \\
\text { Nutricionista del } \\
\text { CEFLI } \\
\text { Revisión diaria } \\
\text { de los registros }\end{array}$ \\
\hline 6 & $\begin{array}{c}\text { Distribución de } \\
\text { las tomas a las } \\
\text { salas de } \\
\text { hospitalización }\end{array}$ & $\begin{array}{l}\text { Biológico: } \\
\text { proliferación de } \\
\text { macroorganismos } \\
\text { patógenos }\end{array}$ & $\begin{array}{c}\text { Temperatura } \\
\text { de las tomas } 5 \\
\pm 2{ }^{\circ} \mathrm{C}, \mathrm{y} \\
\text { tiempo de } \\
\text { entrega en sala } \\
<30 \text { minutos }\end{array}$ & $\begin{array}{l}\text { Temperatura } \\
\text { de las tomas }\end{array}$ & $\begin{array}{c}\text { Registrando } \\
\text { la } \\
\text { temperatura } \\
\text { de las tomas } \\
\text { en el } \\
\text { momento de } \\
\text { la entrega }\end{array}$ & $\begin{array}{l}\text { En cada } \\
\text { entrega }\end{array}$ & $\begin{array}{l}\text { Repartidor del } \\
\text { CEFLI, } \\
\text { encargado de } \\
\text { la recepción } \\
\text { en sala }\end{array}$ & $\begin{array}{l}\text { Desechar las } \\
\text { tomas } \\
\text { Implementar } \\
\text { reparto en } \\
\text { bolsas de } \\
\text { conservación de } \\
\text { frio }\end{array}$ & $\begin{array}{l}\text { Registro de } \\
\text { temperatura de } \\
\text { las tomas } \\
\text { entregadas en } \\
\text { sala }\end{array}$ & $\begin{array}{c}\text { Responsable: } \\
\begin{array}{c}\text { Nutricionista del } \\
\text { CEFLI }\end{array} \\
\text { Revisión diaria } \\
\text { de los registros }\end{array}$ \\
\hline
\end{tabular}

Figura 8. Plan APPCC - CEFLI - 2016

Fuente: elaboración propia 2016

\section{DISCUSION}

Los indicadores de mortalidad, morbilidad y ocupación hospitalaria son mucho más deficientes en situaciones de poco control en el consumo y calidad de alimentos (Diez- García et al., 2012). Considerando esta afirmación es que se requiere la aplicación de procesos de fabricación adecuados en toda la cadena de elaboración y monitorización hasta el momento de su administración. Adhiriendo a lo dicho por Peter Drucker: "Lo que se puede medir se puede mejorar" o lo que es lo mismo "lo que no se puede medir (o no se mide) no se puede mejorar", y dado que la alimentación que brindan los servicios de nutrición de los hospitales representa un pilar fundamental en la recuperación y/o mantenimiento de la salud del paciente hospitalizado, es importante avanzar en la implantación de sistemas de calidad basados en la inocuidad.

De acuerdo con la Guía de práctica clínica del Ministerio de Salud de Argentina (2007), los lactarios deben estar dirigidos por un Licenciado en nutrición, responsable de la organización y administración. Este profesional debe supervisar en forma directa todos los procedimientos involucrados en la elaboración, dispensación, distribución y la supervisión de los aspectos técnicos administrativos. En este sentido el CEFLI cuenta con una nutricionista de planta que cumple el rol de "responsable informal" del centro y otra con cargo interino. Esto muestra un déficit en el recurso nutricionista en relación con el número de fórmulas elaboradas en el centro (653 UC). Por esta razón se propuso al Ministerio de Salud de la provincia de 
Buenos Aires un cambio en la estructura de organización del CEFLI, informalmente llamado "biberoneria" a UNIDAD, la cual contaría con un cargo concursable de Jefatura.

La informalidad encontrada en los medios de registro a través de los cuales se realizaba la solicitud de elaboración de fórmulas daba lugar a la "autorregulación", donde cada sala podía realizar el correspondiente pedido de producción en un formato de planilla distinta, habiéndose encontrado versiones de estas en desuso, hojas en blanco sin formato preestablecido o cualquier elemento que funcione como papel. Además, todos estos datos contenidos en esos "papeles" eran desechados sin un registro previo en bases de datos adecuadas. Este precario sistema se modificó con el diseño e implementación de un nuevo documento que proporciona más información y ordenado de manera de minimizar los errores de interpretación. A tal fin, se redactó el procedimiento para su confección y uso, con el objetivo de mantener una correcta comunicación entre el personal médico encargado de la prescripción de las fórmulas lácteas y el personal del CEFLI encargado de la producción.

El $34 \%$ de la demanda de productos provino de la sala de neonatología y su terapia intensiva, destacándose la prioridad otorgada al consumo de fórmulas líquidas estériles, dado que los pacientes internados en las mismas son una población considerada como de alto riesgo para la infección por patógenos presentes en las fórmulas lácteas en polvo. En este sentido, la bibliografía recomienda que siempre que sea posible, en los entornos asistenciales deben utilizarse las preparaciones liquidas estériles, ya que estas preparaciones no contienen bacterias nocivas. (OMS, 2007; Chantry et al., 2014 y Mestre et al., 2011). Las fórmulas reconstituidas en polvo representaron el $75 \%$ de los pedidos entregados a las salas convirtiéndose en las de mayor consumo. Esto provoco que se instalara sobre ellas el foco de observación con un mayor énfasis puesto durante el proceso de manufactura, por su carácter "no estéril". En consecuencia, su inocuidad microbiológica está vinculada al cumplimiento estricto de BPM durante su fabricación o uso posterior. En este aspecto el estudio realizado por Bustos et al., (2016) muestra una información actualizada sobre los estándares de calidad para un servicio dietético de leche, en un hospital de niños con enfermedades crónicas.

El sistema aquí propuesto para el CEFLI, no se basa en el aseguramiento del proceso por medio de la inspección, sino que propugna en cambio el aseguramiento mediante la adecuada planificación, organización y control de todas las actividades y funciones organizativas para "hacerlo bien desde el comienzo", para garantizar o certificar la calidad de diseño para su uso de acuerdo con lo propuesto por Ishikawa (1994). Durante el estudio se observó que la manipulación inadecuada de las fórmulas ponía en riesgo la inocuidad de estas, lo que genero la necesidad de minimizar el riesgo de contaminación en todo el proceso.

El porcentaje de cumplimiento total del CEFLI en cuanto a las BPM y según se desprende de las dimensiones evaluadas, alcanzo un 49 \% (Figura 3). Situación similar se encuentra en un estudio realizado por Sanabria et al., (2017) en donde el porcentaje de cumplimiento total de las dimensiones evaluadas en lactarios de hospitales públicos de Asunción (Paraguay) alcanza un $52 \%$. Mientras que en las Unidades de Central de Fórmulas Enterales de los Hospitales Públicos de Santiago (Chile) es del 33 \% según el estudio realizado por Lara et al., (2013). El mayor grado de incumplimiento en el CEFLI está asociado con la dimensión organización y administración en la que se observó un $80 \%$ de no conformidades en los parámetros evaluados, en contraposición con el $45 \%$ de incumplimiento en los lactarios de Asunción en Sanabria et al., (2017) y el 53 \% de no conformidades en los hospitales de Santiago en Lara et al., (2013). La segunda dimensión considerada con el mayor incumplimiento en el CEFLI fue el de normas higiénico-sanitarias con el $69 \%$ de incumplimiento de los ítems, siendo del $41 \%$ y del $62 \%$ para los casos de los lactarios de Asunción y de los hospitales de Santiago respectivamente. En el caso del CEFLI, y referido al alto grado de incumplimiento 
en la dimensión de normas higiénico sanitarias, se destacan la falta de personal en el turno tarde para realizar las tareas de limpieza en las áreas de trabajo, falta de trazabilidad de materias primas y producto terminado; técnicas de limpieza y manipulación inadecuada e incumplimiento de normas de higiene por parte del personal, inexistencia de productos químicos con certificación y ficha técnica, carencia de un procedimiento escrito para la limpieza y desinfección tanto de los utensilios como de los equipos, la no utilización de uniformes de trabajo adecuados y la falta de nutricionista para la supervisión de la preparación de las fórmulas. Este último aspecto también coincidente con lo hallado por Lara et al., (2013).

Por otro lado, se subraya el hecho de que se encontraron productos químicos para limpieza que no tenían certificación adecuada para el contacto con alimentos y que eran provisto por el depósito central del hospital en envases no aptos y sin rotulación. Hoy en día, luego de la puesta en práctica del sistema, los insumos de limpieza se adquieren por licitación según las especificaciones de producto provistas por el CEFLI.

Respecto a la dimensión equipamiento y áreas de trabajo, el $43 \%$ no cumple con las BPM. Siendo la más importante la ausencia de productos adecuados para la limpieza y la higiene de manos; equipamiento en mal estado y falta de mantenimiento tanto preventivo como correctivo de estos y las falencias en las instalaciones eléctricas las cuales no son mantenidas de acuerdo con norma vigente. En el caso de los lactarios de Asunción, esta dimensión alcanza un grado de incumplimiento del 58 \% según Sanabria et al., (2017) mientras que en el caso chileno es de 71 \% según lo estudiado por Lara et al., (2013).

La toma de conciencia sobre el impacto que tienen las prácticas higiénicas no adecuadas por parte de los preparadores de fórmulas del CEFLI, en el mantenimiento y la recuperación del estado de salud del paciente resulto exitosa a partir de la puesta en práctica del SGSA.

Se deja para un próximo estudio la posibilidad de realizar una comparativa del estado de situación actual del CEFLI, luego de las modificaciones realizadas a través del SGSA.

\section{CONCLUSIONES}

Resulta claro que el CEFLI presenta condiciones por debajo de lo óptimo en relación con las recomendaciones técnicas. Situación que se vuelve preocupante, considerando que el centro presta servicios en un hospital público de larga trayectoria y alta complejidad. En consecuencia, es de suma necesidad que el CEFLI se encuentre apropiadamente diseñado a fin de responder a las exigencias de un flujo unidireccional para impedir una contaminación cruzada, contar con equipamiento que reúna las condiciones sanitarias requeridas y disponer de recursos humanos debidamente capacitados, aspirando de este modo, a obtener productos inocuos y de alta calidad nutricional.

El APPCC desarrollado durante este trabajo constituyo un gran avance para determinar la criticidad de las etapas de elaboración de fórmulas lácteas en polvo y las acciones correctivas que se deben llevar a cabo para mantener los procesos bajo control. Resultando en una herramienta útil de replicar en cualquier lactario o centro de elaboración de fórmulas infantiles.

EI SGSA implementado sólo verá sus resultados cuando los principios del sistema penetren en el trabajo diario de las personas en todos los niveles organizativos y cuando la estrategia, la estructura, los sistemas y los procesos se alineen para satisfacer las necesidades de los 
clientes internos y externos. Para ello es fundamental la dotación de Recursos Humanos idóneos y motivados, apoyo institucional y respaldo de las autoridades de la Salud.

Por último, no hay que olvidar que el punto de partida de todo sistema de gestión sanitaria debe ser la mejora de la salud de los pacientes a los que atiende. Y aunque la salud no tiene precio, si tiene un costo, el cual debe gestionarse de manera eficaz y eficiente con la intención de hacer sostenibles en el tiempo los sistemas sanitarios públicos.

\section{REFERENCIAS}

AMADOR PORRO, C and CUBERO MENENDEZ, O. Un sistema de gestión de calidad en salud, situación actual y perspectivas en la atención primaria. Rev. cub. salud pública, 2010, 36(2), 175-179.

BORDON RIVEROS, C., AGUILAR-RABITO, A., BERNAL, S. and ARBO, L. Características y prácticas del soporte nutricional enteral en servicios públicos de salud del Departamento Central - Paraguay. Mem. Inst. Investig Cienc Salud, 2016, 14(3), 14-23.

BUSTOS, E., FRANULIC, Y. and FARIAS, N. Estándares de calidad para un servicio dietético de leche, en un hospital de niños con enfermedades crónicas. Rev. chil. nutr., 2016, 43(1), 92-97. [Disponible en]:http://goo.gl/hSpqBZ.

CHANTRY, C.J., DEWEY, K.G., PEERSON, J.M., WAGNER, E.A. and NOMMSEN-RIVERS, L.A. In Hospital Formula Use Increases Early Breastfeeding Cessation Among First-Time Mothers Intending to Exclusively Breastfeed. J Pediatr, 2014, 164(6),1339-1345.e5.

http://dx.doi.org/10.1016/j.jpeds.2013.12.035

DIEZ-GARCIA, W., ARAUJO, A., PACHECO, R., LEANDRO-MERHI, V. and ZAMGIACOMI, E. Gauging food and nutritional care quality in hospitals. J Nutr., 2012, 11, 1-66. https://dx.doi. org/10.1186/1475-2891-11-66

FOOD AND AGRICULTURAL ORGANIZATION/ ORGANIZACIÓN MUNDIAL DE LA SALUD. Código de Prácticas de Higiene para los Preparados en Polvo para Lactantes y Niños Pequeños. CAC/RCP 66 - 2008. Rev. 3. 2009. [Disponible en]: http://goo.gl/VGNSQF [consulta: 23/05/ 2017].

FOOD AND AGRICULTURAL ORGANIZATION/ ORGANIZACIÓN MUNDIAL DE LA SALUD. Código internacional revisado de prácticas. Principios generales de higiene de los Alimentos. CAC/RCP 1-1969. Rev.4. 2003. [Disponible en]: http://goo.gl/Rr3xSw [consulta: 23/05/ 2017].

FOOD AND AGRICULTURAL ORGANIZATION/ WORLD HEALTH ORGANIZATION. Safe preparation, storage and handling of powdered infant formula: guidelines. Geneva: WHO Press, World Health Organization; 2007. [Disponible en]:http://goo.gl/jNz6B5

HUIZA GUARDIA, G. Satisfacción del usuario externo sobre la calidad de atención de salud en el hospital de la base naval del Callao. Tesis para optar el Grado Académico de Magister en Enfermería. Mención Gestión en Enfermería. Universidad Mayor de San Marcos. Facultad de Medicina, Lima, Perú, 2006. [Disponible en]: http://goo.gl/odBrtk [Consulta: 23/5/17]. 
HURTADO DE BARRERA, J. Metodología de la Investigación: guía para la comprensión holística de la ciencia (4ª . Ed.). 2010. Caracas. Editorial SYPAL. p.325. ISBN 980-6306-06-6

ISHIKAWA, K. Introducción al Control de Calidad. Ediciones Díaz de Santos, Madrid, 1994.

LARA GONZALEZ, S., DOMECQ JENDRES, C. and ATALAH SAMUR, E. Evaluación de buenas prácticas de manufactura en la elaboración de fórmulas enterales en hospitales públicos de Santiago, Chile. Nutrición Hospitalaria [en línea] 2013, 28 (Noviembre-Diciembre): [consulta: 9/03/2017] Disponible en: http://goo.gl/sNf9i5. ISSN 0212-1611. http://dx.doi. org/10.3305/nh.2013.28.6.6864

MESTRE, FG., MASUDA, FC, BREA, SCM, LEVY, FL, PICO, RM and BLASI, QS. Evaluación del riesgo de infecciones alimentarias en pacientes internados en un hospital pediátrico de alta complejidad y su sistema de prevención. Rev. chil. nutr., 2011, 38(1) http://dx.doi. org/10.4067/S0717-75182011000100004.

MINISTERIO DE SALUD DE CHILE. Norma técnica para servicios dietéticos de leche (SEDILE) y central de fórmulas enterales (CEFE). Santiago: Chile. 2012. p.67. http://goo. gl/9eEHBF.

MINISTERIO DE SALUD DE ARGENTINA. Guía de Calidad de los Servicios de Salud. Programa Nacional de Garantía de la Calidad de la Atención Médica. Guía Práctica Clínica de Soporte Nutricional Enteral y Parenteral en pacientes hospitalizados y domiciliarios. Resolución No 1548. Buenos Aires, Argentina, 2007 [en línea] Disponible en: http://goo.gl/ ZK5bLw. [consulta: 23/05/2017].

PARRA FLORES, J., JUNEJA, V., GARCIA DE FERNANDO, G. and AGUIRRE, J. Variability in Cell Response of Cronobacter sakazakii after Mild-Heat Treatments and Its Impact on Food Safety. Frontiers in Microbiology, 2016, 7, 535. https://dx.doi.org/10.3389/fmicb.2016.00535

RACHON, G, PEÑALOZA, W., BREEEUWER, P., JIEWEN GUAN, KNIGHT, A., CAMPELOS, I. and GIBBS, P. Poor hygiene practices in infant formulae reconstitution and inappropriate storage of feeding bottles can cause spoilage issues by Serratia marcescens. Food Control, 2017, 79,150-155. https://dx.doi.org/10.1016/j.foodcont.2017.03.046

SANABRIA, M., MOREL, L and AGUILAR, G. Caracterización general de Lactarios de Hospitales de Referencia de Asunción y Departamento Central. Pediatr. (Asunción), 2017, 44(2),143-147. http://dx.doi.org/10.18004/ped.2017.agosto.143-147.

SIQUEIRA, R. F., Da SILVA, N., AMSTALDEN, V.C., KAJSIK, M., FORSYTHE, S. and PEREIRA, J.L. Screening for Cronobacter Species in Powdered and Reconstituted Infant Formulas and from Equipment Used in Formula Preparation in Maternity Hospitals. Ann Nutr Metab, 2013, 63, (1-2),62-68. https://dx.doi.org/10.1159/000353137

\section{BIOGRAFIA}

\section{Silvia Alejandra Marteau}

Miembro de la carrera de personal de apoyo a la investigación científica y tecnológica. Comisión de Investigaciones Científicas provincia de Buenos Aires (CIC).

Profesional Principal Centro de Investigación y Desarrollo en Crio tecnología en Alimentos. 
UNLP. CONICET. CIC

Profesor Adjunto de Economía para la carrera de ingeniería industrial. Universidad Tecnológica Nacional - Facultad Regional La Plata. Argentina.

Máster en Administración de Empresas - Ingeniera química.

\section{Luis Héctor Perego}

Profesor Adjunto Costo y Presupuesto para la carrera de ingeniería industrial. Universidad Tecnológica Nacional - Facultad Regional La Plata. Argentina.

Máster en Administración de Empresas - Ingeniero químico

\section{María Cecilia Gaillard}

Miembro de la carrera de personal de apoyo a la investigación científica y tecnológica. Comisión de Investigaciones Científicas provincia de Buenos Aires (CIC).

Profesional Adjunto Instituto de Investigaciones Pediátricas (IDIP), Ministerio de Salud provincia de Buenos Aires. Argentina.

Máster en Administración de Empresas - Ingeniera en alimentos 